\title{
AISLAMIENTO, CARACTERIZACIÓN E IDENTIFICACIÓN DE BACTERIAS DIAZOTRÓFICAS DE LA RIZÓSFERA DEL CULTIVO DE Olea eUropea “OLIVO” EN TACNA PERÚ
}

\section{ISOLATION, CHARACTERIZATION AND IDENTIFICATION OF DIAZOTROPHIC BACTERIA IN THE RHIZOSPHERE OF Olea europea "OLIVE” CROP IN TACNA PERU}

\author{
Claudia Clavijo $^{1}$, Virginia Chipana ${ }^{1}$, Jhon Centeno ${ }^{1}$, Doris Zúñiga ${ }^{2}$ y Carlos Guillén ${ }^{1}$
}

\begin{abstract}
Resumen
Se aislaron y caracterizaron 104 cepas de bacterias diazotróficas nativas de la rizósfera del olivo en el Fundo San Martín de Porres en Tacna - Perú. Se encontraron correlaciones entre las poblaciones bacterianas con la materia orgánica, fósforo, $\mathrm{pH}$ del suelo, tipo de riego y profundidad de la raíz. Las bacterias fueron caracterizadas en base a su capacidad promotora de crecimiento, mediante la producción de Ácido Indol Acético (AIA), solubilización de fosfatos, germinación de semillas de alfalfa y crecimiento en Medio Mineral sin Nitrógeno. El 58.65\% de cepas produjo AIA, el $25.96 \%$ solubilizó fosfato tricálcico, el $45.2 \%$ incrementó significativamente la germinación de las semillas de alfalfa con respecto al control y hubo un crecimiento máximo de $6 \times 10^{8}$ UFC.ml $^{-1}$ en la prueba de crecimiento en Medio Mineral sin Nitrógeno. Posteriormente, se seleccionaron las 20 mejores cepas, donde la cepa $11 \mathrm{~A}$ presentó el mejor porcentaje de ponderación (69.02\%) respecto a las cuatro variables analizadas. Asimismo, los mejores resultados fueron para la cepa 11A (AIA $46.47 \mu \mathrm{g} / \mathrm{ml}$ ), cepa 14A $\left(5.84 \mathrm{~cm}^{2}\right.$ de área de solubilización de fosfato tricálcico) y cepa 3A (45.83\% de porcentaje de germinación). El análisis molecular del gen 16S rRNA permitió identificar las especies: Novosphingobium scionense, Novophingobium resinovorum, Klebsiella pneumoniae subsp. rhinoscleromatis, Erwinia tasmaniensis, Raoultella planticola, Azotobacter vinelandii, Burkholderia metallica y Rhizobium massiliae. Los resultados permiten sugerir que estas bacterias pueden ser utilizadas para ensayos a nivel de invernadero y posteriormente a nivel de campo como posibles promotores del crecimiento vegetal.
\end{abstract}

Palabras clave: Diazótrofos, promotor del crecimiento vegetal, ácido indol acético (AIA), solubilización de fosfatos.

\begin{abstract}
104 bacteria strains native diazotrophic strain from the rhizosphere of olive in Fundo San Martín de Porres in Tacna-Peru. Correlations were found between bacterial populations with organic material, phosphorous, soils $\mathrm{pH}$, kind of irrigation and root deep. The bacteria were characterized based on their ability growth promoter by production of indole acetic acid (IAA), phosphate solubilization, alfalfa seed germination and growth in Mineral Medium without Nitrogen. 58.65\% of strains produced IAA, $25.96 \%$ solubilized tricalcium phosphate, $45.2 \%$ significantly increased the germination of alfalfa seeds with respect control and maximum growth was $6 \times 10^{8} \mathrm{CFU} . \mathrm{ml}^{-1}$ in the growth trial in Mineral Medium without Nitrogen. Subsequently top 20 strains were selected, where strain $11 \mathrm{~A}$ had the best weighting analyzed (69.02\%) over the four variables analyzed. Also, the best results were to: $11 \mathrm{~A}$ strain (IAA $46.47 \mu \mathrm{g} / \mathrm{ml}) ; 14 \mathrm{~A}$ strain $\left(5.84 \mathrm{~cm}^{2}\right.$ area of tricalcium phosphate solubilization); 3A strain (45.83\% of germination percentage). Molecular analysis of 16S rRNA gene allowed to identify the species: Novosphingobium scionense, Novophingobium resinovorum, Klebsiella pneumoniae subsp. rhinoscleromatis, Erwinia tasmaniensis, Raoultella planticola, Azotobacter vinelandii, Burkholderia metallica and Rhizobium massiliae. Results suggest that these bacteria can be used in greenhouse essays and then at the field as possibly plant growth promoter.
\end{abstract}

Key words: diazotrophs, plant growth promoters indole acetic acid (IAA), phosphate solubilization.

\section{Introducción.}

Actualmente la gran mayoría de cultivos agrícolas de Tacna y el Perú depende de los fertilizantes químicos sintetizados, los cuales proporcionan nutrientes asimilables por las plantas, buscando optimizar los procesos de producción. El uso indiscriminado de 
fertilizantes químicos, ocasiona contaminación de cuerpos de agua y suelos, sumando al incremento de los costos de producción y el impacto negativo en la salud animal y humana. El empleo de cepas de microorganismos con un alto potencial de acción sobre el crecimiento y desarrollo de las plantas y el estudio de la diversidad biológica de sus patógenos son factores clave en su control y por tanto, en el manejo integral de los cultivos (Olalde, 1998).

El suelo es un ecosistema de enorme riqueza microbiana. Los estudios sobre los microorganismos del suelo son numerosos, sin embargo hasta la fecha no se ha determinado completamente la biodiversidad necesaria, en lo que se refiere a microorganismos, para que un suelo agrícola funcione de manera óptima (Stewart, 1991). El grupo de bacterias conocido como PGPR (Plant Growth Promoting Rhizobacteria), son bacterias que colonizan la raíz y estimulan significativamente el crecimiento de plantas. Los microorganismos diazótrofos, organismos de vida libre capaces de fijar nitrógeno, descritos desde el siglo pasado, han sido objeto no solo de estudio en microbiología de suelos, sino también en el desarrollo de productos biológicos comerciales. El análisis del gen del RNA ribosomal 16S suministra información importante sobre la identidad de bacterias diazotróficas y permite establecer las relaciones filogenéticas entre individuos del mismo agroecosistema (Jiménez, 2007).

La ciudad de Tacna tiene como cultivo potencial el cultivo del olivo, que abarca más del $60 \%$ de la producción nacional y en donde se registra el mayor rendimiento de olivo a nivel nacional (6.4 t/ha) (Navas, 2010). Actualmente no se cuenta con una fertilización orgánica eficiente y rentable para este cultivo, durante los 50 años del cultivo su fertilización ha sido principalmente química, provocando eutrofización de los suelos y se proyecta una disminución en el rendimiento de los cultivos en los próximos años. Siendo las aplicaciones de abono de fondo compost entre 30 a 40 kilos por planta cada 2 años y los niveles de fertilización química por ha/ olivo/año están en N-P-K-Ca-Mg-S igual a 80-4080-20-10-30, respectivamente.

Por lo tanto, el objetivo de este trabajo fue estudiar las bacterias diazotróficas nativas de la rizósfera del cultivo de olivo y su posterior uso como promotoras del crecimiento vegetal que tendrían un potencial para ser utilizadas como inoculantes.

\section{Materiales y métodos.}

Lugar de muestreo.

Las muestras de la rizósfera fueron colectadas de las áreas destinadas para el cultivo exclusivo de Olea europea crecidas en el fundo San Martín de Porres en La Yarada -Tacna, ubicada a $10 \mathrm{msnm}$. Los suelos son del tipo franco arenoso y arena franca. Las coordenadas son: latitud 181241.3 y longitud 7031
25.9, la temperatura promedio fue entre $24.8-27.8^{\circ} \mathrm{C}$, el clima es templado, desértico y con amplitud térmica moderada.

Aislamiento de bacterias diazotróficas.

Para el aislamiento se realizó la toma de muestra aplicando un muestreo aleatorio sistemático ordenado por el tipo de riego y profundidad de la raíz. Se consideraron 129 hectáreas o áreas $(\mathrm{N})$ que se destinaban para el cultivo exclusivo de olivo. Se tomaron 30 unidades muestrales (n). Se determinó el inicio de la selección de la muestra $(\mathrm{K})$ mediante la siguiente fórmula:
Donde:

$$
\mathrm{K}=\mathrm{N} / \mathrm{n}
$$
$\mathrm{N}=$ Total de áreas a muestrear
$\mathrm{n}=$ Muestras tomadas
K= Inicio de la selección de la muestra

Al aplicar la fórmula se determinó el inicio de selección de muestra $\mathrm{k}=4$ que por cada unidad muestral se tomaron 8 submuestras mediante un muestreo aleatorizado en zig-zag. El aislamiento fue utilizando la técnica del Número Más Probable (NMP) (Zapater, 1975), con los resultados obtenidos se hizo análisis de Pearson que determinó las correlaciones entre las variables fisicoquímicas, la enumeración de bacterias diazotróficas del suelo, la profundidad de la raíz y el tipo de riego, utilizando el software Statgraphics Centurion XV.

A partir de los tubos positivos en el NMP, se tomó una alícuota del MMSN (composición por litro: $\mathrm{KH}_{2} \mathrm{PO}_{4} 0.15$ g, $\mathrm{Na}_{2} \mathrm{HPO}_{4}$. $2 \mathrm{H}_{2} \mathrm{O} 0.354 \mathrm{~g}, \mathrm{NaCl} 0.02$ g, $\mathrm{CaCl}_{2} 0.01$ g, Fe $\mathrm{Cl}_{3} 0.0034$ g, $\mathrm{Na}_{2} \mathrm{Mo} \mathrm{O} \mathrm{O}_{4} 2 \mathrm{H}_{2} \mathrm{O}$ 0.0108 g, Manitol 10 g, Sacarosa 15 g, Agar agar 15 g, Azul de bromotimol al $0.4 \% 5 \mathrm{ml}, \mathrm{pH} 7$ ), se sembró por agotamiento en placas Petri con MMSN que fueron incubadas a $28{ }^{\circ} \mathrm{C}$ por $72 \mathrm{~h}$. Para la purificación se tomó una porción de la colonia con el asa de Kollé y se mezcló en $1 \mathrm{ml}$ de SSF $(0.85 \%$ de $\mathrm{NaCl}$ ) con tween 80 al $0.1 \%$. Este homogenizado se volvió a sembrar en placas con MMSN. Después de la incubación las colonias se sometieron a observaciones microscópicas mediante coloración Gram para determinar la pureza, se realizó la caracterización microscópica y macroscópica de las colonias aisladas que fueron procesadas utilizando el software Statgraphics Plus Centurion XV.

Cuantificación de la producción de AIA.

Se utilizó la metodología de Naik \& Sakthivel (2006). Se empleó el reactivo de Salkowski $\left(\mathrm{FeCl}_{3}\right.$. $6 \mathrm{H}_{2} \mathrm{O} 0.01 \mathrm{M} \mathrm{y} \mathrm{H}_{2} \mathrm{SO}_{4} 7.1 \mathrm{M}$ ), se tomó una colonia bacteriana y se sembró en medio B suplementado con triptófano al 1\% (composición por litro glucosa $5 \mathrm{~g}$, $\mathrm{Na}_{2} \mathrm{HPO}_{4} 1 \mathrm{~g}, \mathrm{NH}_{4} \mathrm{NO}_{3} 0.4 \mathrm{~g}, \mathrm{NaCl} 0.2, \mathrm{MgSO} 4.7 \mathrm{H}_{2} \mathrm{O}$ $0.4 \mathrm{~g}$, triptófano $1 \mathrm{~g}$ ) se incubó por 7 días a $28^{\circ} \mathrm{C}$. Luego se centrifugó a $4000 \mathrm{rpm}$ por $15 \mathrm{~min}$. Se tomó $1 \mathrm{ml}$ del sobrenadante, se pasó a un tubo de ensayo y 
se agregó $1 \mathrm{ml}$ del reactivo de Salkowsky. Incubándose en oscuridad a temperatura ambiente de $25^{\circ} \mathrm{C}$ por 30 min., la lectura se realizó por espectofotometría en una absorbancia de $530 \mathrm{~nm}$. Prueba de solubilización de fosfato tricálcico.

Se utilizó la metodología empleada por Nautiyal (1999). Las bacterias aisladas se reactivaron a partir de un cultivo puro en tubos con $10 \mathrm{ml}$ de Caldo Tripticasa de Soya, luego se incubaron a $28^{\circ} \mathrm{C}$ por 48 h hasta llegar a una población aproximada de $10^{8}$ $\mathrm{cel} / \mathrm{ml}$, mediante recuento en cámara de Neubauer. Posteriormente se sembró una alícuota de $10 \mu \mathrm{l}$ de cultivo bacteriano por triplicado en el Medio National Botanical Research Institute's Phosphate (NBRIP) con fosfato tricálcico dispuesto en placas Petri e incubándose a $28^{\circ} \mathrm{C}$ por 15 días, donde se evaluó el diámetro de las colonias y halos, empleándose la siguiente fórmula para determinar el área del halo de solubilización:

$$
A=\left(R^{2}-r^{2}\right) * \pi
$$

Donde: $\quad$ R: Radio de la colonia más el halo r: Radio de la colonia

Se obtuvo la media aritmética de los resultados independientemente para cada bacteria

Efecto bacteriano en la germinación de semillas de Medicago sativa "alfalfa".

Se utilizó la metodología empleada por Zúñiga (2012) se reactivaron las bacterias en tubos con $10 \mathrm{ml}$ de MMSN, cada bacteria fue sembrada por triplicado, se incubó a $28{ }^{\circ} \mathrm{C}$ por 3 días. Luego se realizó el recuento en Cámara de Neubauer, los recuentos superiores a $10^{6} \mathrm{cel} / \mathrm{ml}$ fueron diluidos hasta obtener $10 \mathrm{ml}$ a dicha concentración. Las semillas de alfalfa fueron desinfectadas, mediante un enjuague en agua destilada estéril, alcohol al 70\% por 3 min., lejía al 3\% por 3 min. y finalmente dos enjuagues con agua destilada para eliminar el exceso de lejía. Estas semillas se colocaron a secar y se embebieron por 30 min., para el caso del control, las semillas fueron embebidas en $10 \mathrm{ml}$ de MMSN, luego se colocaron 50 semillas por placa y se agregó $10 \mathrm{ml}$ de SSF a cada placa para mantener la humedad. Se incubaron a $25^{\circ} \mathrm{C}$ por 48 h, luego se evaluó el porcentaje de germinación mediante la siguiente fórmula:

$$
\text { \% GERMINACIÓN: } \frac{\mathrm{A}}{\mathrm{B}} \text { X } 100
$$

Donde: $\quad$ A: $\mathrm{N}^{\circ}$ de semillas germinadas $\mathrm{B}: \mathrm{N}^{\circ}$ Total de semillas

Se obtuvo el valor central de los resultados independientemente para cada bacteria, este valor fue utilizado para selección. Se realizó una evaluación del efecto bacteriano en la germinación mediante la prueba de Dunnett con un nivel de significancia del $5 \%$ mediante el software Statgrtaphics Centurion XV.
Crecimiento en el MMSN método turbidimétrico de Mc Farland (1907).

Se reactivaron las bacterias diazotróficas a partir de cultivos puros por triplicado en tubos con $10 \mathrm{ml}$ de MMSN, las que fueron incubadas a $28^{\circ} \mathrm{C}$ por $72 \mathrm{~h}$. Luego de la incubación se realizó la comparación de la turbidez presentada en cada tubo con los tubos de la escala turbidimétrica de Mc Farland.

Análisis estadístico.

La selección de bacterias diazotróficas fue realizada mediante la sumatoria de promedios ponderados de las pruebas realizadas. Se estableció la ponderación de acuerdo al grado de importancia y se halló el promedio máximo para cada prueba, utilizando la siguiente fórmula:

$$
\mathrm{P}_{\mathrm{P}}=\frac{\overline{\mathrm{X}}}{\mathrm{M}} \times \mathrm{P}_{\mathrm{i}}
$$

Donde: $\quad \overline{\mathrm{X}}=$ Promedio de cada resultado $\mathrm{M}$ = Promedio máximo de la prueba $\mathrm{P}_{\mathrm{i}}=$ Ponderado de la prueba $\mathrm{P}_{\mathrm{P}}=$ Promedio ponderado

Finalmente, se seleccionaron 20 cepas que obtuvieron las mayores sumatorias de promedios ponderados, para luego ser identificadas molecularmente.

Caracterización molecular de las cepas seleccionadas.

A partir de pellets de las cepas seleccionadas, se realizó la extracción de ADN, mediante la técnica del Salting Out, técnica más apropiada para las bacterias diazotróficas, utilizando el kit de extracción de ADN: Wizard Genomic DNA isolation - Promega. Se llevó a cabo la amplificación del gen 16S rRNA, para la cual se utilizaron los siguientes primers: primer: $16 \mathrm{SJ}$ (787 F: 10 picomoles) (1515R: 10 picomoles), primer: 16SA (1525 R: 10 picomoles) (27F: 10 picomoles). Las condiciones de amplificación fueron: 1 ciclo de desnaturalización inicial $95^{\circ} \mathrm{C}$ x 15', 35 ciclos de desnaturalización $94^{\circ} \mathrm{C}$ x $15^{\prime}$ ', alineamiento $55^{\circ} \mathrm{C}$ x 60’’, extensión $72^{\circ} \mathrm{C}$ x 1 ' 30'’ y 1 ciclo de extensión final $72^{\circ} \mathrm{C}$ x $10^{\prime}$. Los fragmentos de $\mathrm{ADN}$ fueron separados en gel de agarosa al $1 \%$, fotografiados después con colorante bromuro de etidio y las bandas visualizadas fueron grabadas. El secuenciamiento del gen 16S rRNA, fue realizado mediante un análisis directo de cada una de las dos hebras en un analizador genético automático AB3130. Posteriormente se llevó la identificación molecular utilizando las bases de datos: Blast server for bacterial identification, Ribosomal Database Project, BiBi Database (Mignard \& Flandrois, 2006) y la base Ez Taxon (Kim et al., 2012). 
Resultados.

Aislamiento de diazotrofos.

Se aislaron 104 cepas de bacterias diazotróficas de la rizósfera del cultivo del olivo. Los recuentos de bacterias obtenidos por el método del NMP fluctuaron a partir de $23 \mathrm{NMP} / \mathrm{g}$ hasta $>1.1 \times 10^{4}$ NMP/g (Tabla 1).

En la Tabla 2 mediante el análisis de correlación de Pearson se encontró que las bacterias diazotróficas aisladas tienen una correlación con la materia orgánica, fósforo, pH del suelo, profundidad de la raíz y tipo de riego. En la caracterización fenotípica de las 104 cepas aisladas se obtuvieron 6 grupos más numerosos con características microscópicas y macroscópicas en común, la características de bacilo largo ovoide y la forma de colonia circular, regular, elevada, lisa, crema brillante, fueron las más frecuentes entre las cepas (Tabla 3).

Cuantificación de la producción de AIA.

De las 104 cepas aisladas el $58.65 \%$ produjo AIA, mientras que el $41.35 \%$ no produjo esta hormona (datos no mostrados). Respecto a las 20 cepas seleccionadas, 10 cepas (50\%) producen AIA en un rango de 2.42 hasta $46.47 \mu \mathrm{g} / \mathrm{ml}$, este último valor correspondió a la cepa 11 A Sphingobium scionense que tiene la mayor producción de AIA; seguida por la bacteria 7 A Rhizobium massiliae con $37.78 \mu \mathrm{g} / \mathrm{ml}$ (Tabla 4).

Solubilización de fosfato tricálcico.

De las 104 cepas un 25.96\% solubilizó fosfato tricálcico, mientras que un $74.04 \%$ no lo solubilizó (datos no mostrados). De las 20 bacterias seleccionadas 5 (25\%) solubilizaron fosfatos, mientras que 15 (75\%) no lo hicieron, asimismo el rango de solubilización estuvo entre $0.3-5.84 \mathrm{~cm}^{2}$, este último valor correspondió a la cepa 14 A Erwinia tasmaniensis que fue la mayor solubilizadora de este compuesto (Tabla 4).

Germinación de semillas de alfalfa.

Respecto a las 104 cepas aisladas de acuerdo a la prueba de Dunnett se observó que 47 (45.2\%) incrementaron significativamente la germinación hasta en un $129 \%$ (cepa 3 A) con respecto al control; seguida de la cepa 12 G con $127 \%$. También 44 cepas de bacterias (42.3\%) no produjeron ningún efecto significativo con respecto al control y 13 cepas (12.5\%) redujeron la germinación (Tabla 5).

Crecimiento en MMSN.

Según esta escala las cepas tuvieron valores $<1.5$ x $10^{8}$ UFC. $\mathrm{ml}^{-1}$ como mínimo y como máximo valores de $6 \times 10^{8}$ UFC. $l^{-1}$ (Tabla 4).

Identificación molecular de bacterias diazotróficas seleccionadas.

Se identificaron molecularmente 20 bacterias fijadoras de nitrógeno. El análisis del gen 16S rRNA, mediante la base de datos Ez Taxon, permitió identificar hasta especie un 55\% (11 cepas) y hasta género un $45 \%$ (9 cepas). Las especies identificadas fueron: Novosphingobium scionense, Novosphingobium resinovorum, Burkholderia metallica, Rhizobium massiliae, Klebsiella pneumoniae subsp. rhinoscleromatis, Azotobacter vinelandii, Erwinia tasmaniensis y Raoultella planticola (Tabla 6).

\section{Discusión.}

Los resultados de esta investigación evidencian la presencia de bacterias diazotróficas fijadoras de nitrógeno en la rizósfera del olivo en su hábitat natural en una zona costera. Entre los dos bloques muestreados, el riego por goteo donde las raíces se encuentran a $60 \mathrm{~cm}$ de profundidad, presentaron recuentos más elevados en promedio y en comparación con las áreas donde el riego es por microaspersión y las raíces están a una profundidad de 30 cm (Tabla 1). Según Calvo et al. (2008) y Ogata \& Zúñiga (2005) obtuvieron recuentos de bacterias presuntivas de Azotobacter spp. hasta $70 \mathrm{NMP} / \mathrm{g}$ y $10^{2} \mathrm{NMP} / \mathrm{g}$ de suelo respectivamente, los recuentos obtenidos en el presente trabajo son mayores a los obtenidos por estos autores, indicando así la carga total de bacterias diazotróficas presentes en los suelos del olivo. Según la técnica utilizada por los autores antes mencionados, reportan como microorganismos presuntivos de Azotobacter, sin embargo en este trabajo se aislaron entre las bacterias seleccionadas el género Azotobacter, siendo el resto otras especies bacterianas.

Estas bacterias diazotróficas fueron aisladas en un suelo con características fisicoquímicas como el pH que osciló entre 5.76-7.45, la materia orgánica estuvo entre $0.2-1.2 \%$, el fosfato estuvo entre 13.59 a 107.53 ppm (datos no mostrados). Estas variables se correlacionaron con la concentración de bacterias encontradas en el suelo, la profundidad de la raíz y el tipo de riego. Obteniéndose que a mayor profundidad se encontró mayor número de bacterias, respecto al $\mathrm{pH}$ en general las bacterias prefieren $\mathrm{pH}$ neutros a ligeramente alcalinos. Referente al fosfato la correlación es positiva, esto se debería a que las bacterias están utilizando esta sal para su metabolismo (Tabla 2). Estos resultados concuerdan con lo mencionado por Frioni (1999) que la fijación biológica de nitrógeno en las bacterias diazotróficas requiere de gran cantidad de energía por lo que la cantidad de materia orgánica en la rizósfera es fundamental para el desarrollo de estos microorganismos.

En la Tabla 3 se han agrupado las cepas aisladas de acuerdo a sus características macroscópicas y microscópicas comunes, los grupos más numerosos fueron 6. El primer grupo (etiquetas 1-1) guardan relación con cepas típicas de Azotobacter se hallaron 23 cepas con dichas características; las etiquetas 5-2 contienen enterobacterias identificadas como: 5 A Klebsiella pneunoniae subsp. rhinoscleromatis, cepas 
14 A y 14 B de Erwinia tasmaniensis, éstas se encuentran ubicadas en el mismo grupo lo que coincide también con la identificación molecular, sin embargo comparten características con cepas 7 A Rhizobium massiliae y $9 \mathrm{~F}$ Novosphingobium sp. Las cepas 9K, 11 A, 26B de Sphingobium scionense y 3 A, 3B, 12 G de Novosphingobium sp. (etiquetas 4-2) se encuentran ubicadas en un mismo grupo lo que coincide también con la identificación molecular. No obstante, otras cepas como 27F Novosphingobium sp., 11I Novosphingobium sp. y 16B $N$. resinovorum, se encuentran en otros grupos, esto sería debido a que habrían cepas bacterianas con características diferentes entre un mismo género.

La capacidad de producir fitohormonas como auxinas es una característica deseable de un PGPR (Vessey, 2003). Un 58.65\% de las 104 cepas aisladas produjo AIA (datos no mostrados). De las 20 cepas seleccionadas produjeron AIA entre 2.42 hasta 46.47 $\mu \mathrm{g} / \mathrm{ml}$ (Tabla 4), estos resultados concuerdan con Celis \& Gallardo (2008), que obtuvieron en el medio BT a los 6 días un máximo de $60 \mu \mathrm{g} / \mathrm{ml}$ de AIA con una cepa de Azotobacter vinelandii. Se han reportado bacterias Azotobacter como productoras de AIA, una de las auxinas más estudiadas hasta el momento (Tsavkelova et al., 2006; Mrkovacki \& Milic, 2001; Ahmad et al., 2005; García \& Herraiz, 1987). Las bacterias evaluadas con características presuntivas para Azotobacter no produjeron AIA, este grupo de bacterias estarían dentro del $44 \%$ de cepas de Azotobacter evaluadas por Rico (2009) que no dieron una reacción positiva para la producción de AIA. Obando et al. (2010) en un trabajo sobre bacterias diazotróficas del eucalipto, encontraron un máximo $49.57 \mu \mathrm{g} / \mathrm{ml}$ de AIA, valor que es similar al obtenido en esta investigación.

La capacidad que poseen algunas bacterias habitantes de la rizósfera para solubilizar fosfato, les permite ser consideradas como bacterias promotoras del crecimiento vegetal (Rico, 2009). De 104 cepas aisladas un $25.96 \%$ solubilizó fosfato tricálcico (datos no mostrados); de 20 bacterias seleccionadas el rango de solubilización estuvo entre 0.31 y $5.84 \mathrm{~cm}^{2}$ (Tabla 4). Estos resultados concuerdan con los reportados por Rico (2009) donde los halos de solubilización varían de $0.11 \mathrm{~cm}^{2}$ a $5.43 \mathrm{~cm}^{2}$ producidos por las cepas de Azotobacter. En nuestra investigación el género Azotobacter no solubilizó el fosfato tricálcico, mientras que los géneros que sí solubilizaron fueron: Burkholderia, Erwinia, Raoultella y klebsiella (Tabla 4).

Se emplearon semillas de alfalfa en las que se aplican microorganismos diazotróficos, que parecen tener una respuesta más rápida a los exudados celulares producidos por la interacción con estos microorganismos (Ogata et al., 2008).

Respecto al efecto bacteriano en la germinación de las semillas de alfalfa se encontró que la cepa 3A
Novosphingobium sp. presentó el máximo valor de germinación de $45.83 \%$ (Tabla 4), no produciendo AIA, por lo que se presumiría la producción de otras hormonas que no estarían siendo determinadas por la metodología aplicada. Asimismo, se encontró que el $45.2 \%$ de las bacterias diazotróficas aisladas, presentaron un incremento significativo en el porcentaje de germinación con respecto al control en 48 horas de incubación llegando hasta un 129\% de incremento de la germinación (Tabla 5). En contraste a los resultados reportados por Ogata et al. (2008) que evaluaron el efecto de diferentes bacterias diazotróficas aisladas de la rizósfera de árboles de “Tara” y evaluadas a las 24 horas en semillas de alfalfa, mostraron que el $50 \%$ de los tratamientos incrementaron significativamente la germinación de estas semillas, obteniendo hasta un incremento del porcentaje de germinación de $214 \%$ con respecto al control. Esto es mayor a los resultados del presente trabajo.

Para evaluar el crecimiento en el MMSN se designó un valor a partir de 0 a 3 de acuerdo a las equivalencias con los tubos de la escala de Mc Farland, de las 104 cepas aisladas sólo el 12.5\% obtuvo crecimientos equivalentes a 6 × $10^{8} \mathrm{UFC}_{\mathrm{Ul}} \mathrm{m}^{-1}$ (escala 3) (datos no mostrados). No obstante, el $40 \%$ de las 20 cepas seleccionadas presentó un crecimiento equivalente a la escala 3 (Tabla 4). Esta variable fue importante para estimar la capacidad de cepas con potencial para la producción de inoculantes.

En la Tabla 4 se observa la ponderación aplicada a las cuatro variables, se reporta que la cepa $11 \mathrm{~A}$ obtuvo la mayor sumatoria de ponderados 69.02\%, destacando la producción de AIA, la germinación de semillas, el crecimiento en el MMSN estuvo en la escala 3 de Mc Farland, sin embargo, no se detectó la capacidad de solubilizar fosfatos.

En la tabla 6 respecto a la identificación molecular de las bacterias diazotróficas, se trabajaron con 4 bases de datos: Blast, Ribosonal Database, Bibi Database y Ez Taxon. Para la identificación se tomó la especie reportada por la base Ez Taxon. Considerando como identificadas hasta especie las que tuvieron más del 99\% de similitud que fueron 11 cepas (55\%) e identificadas hasta género (posibles nuevas especies) que presentaron igual o menos del 99\% de similitud reportándose como géneros 9 cepas (45\%), en éstas se podrían considerar otros estudios genéticos para llegar a identificarlas. Velezmoro et al. (2011) utilizaron también la base Ez Taxon para la identificación genotípica de Bacillus sp.

La identificación con Ez Taxon implica 2 pasos diferentes: etapa inicial de búsqueda para encontrar las secuencias potencial y estrechamente relacionadas y una etapa de alineamiento por pares para calcular los valores de similitud de secuencias de consulta y las secuencias identificadas por el paso. Ez Taxon usa un nuevo algoritmo que considera búsquedas en el 
BLASTN con 4 secuencias de consulta diferentes (Myers \& Miller, 1988).

La cepa 9K fue identificada como Sphingobium scionense por Ez Taxon con un $99.61 \%$, las otras 3 bases la reportaron como Sphingobium yanoikuyae, pero la segunda opción en Ez Taxon fue Sphingobium yanoikuyae. La cepa 7 A Rhizobium massiliae fue identificada por el Ez Taxon con un 99.8\%, a diferencia de las otras bases de datos que reportan como especies a Agrobacterium tumefaciens (Blast), Rhizobium radiobacter (Ribosomal Database) y Beijerinckia fluminensis (Bibi Database) (Tabla 6).

El 50\% de las cepas identificadas molecularmente correspondieron a la familia Sphingomonadaceae (Tabla 6); en esta familia se encontró en un $60 \%$ en la etiqueta fenotípica 4-2 (Tabla 3). El 85\% de cepas que se encuentran en esta etiqueta fueron seleccionadas para su identificación molecular debido a sus características fisiológicas y bioquímicas (Tabla 4), lo que indicaría la efectividad de esta familia como rizobacterias promotoras del crecimiento vegetal en el cultivo del olivo.

La familia Enterobacteriacea representó un 20\% del total de cepas identificadas molecularmente (4 cepas). Las cepas $13 \mathrm{C}$ y $30 \mathrm{D}$ se reportan como Azotobacter sp. debido a su bajo porcentaje de similitud con Azotobacter vinelandii, a diferencia de la cepa 11D identificada como $A$. vinelandii, cuyo porcentaje de similitud fue de $99.82 \%$ reportado por Ez Taxon (Tabla 6).

En la extracción de ADN el kit Promega de lisis nuclear y proteinasa $\mathrm{K}$, permitió extraer el ADN de todas las cepas incluyendo la cepa 17C de Bacillus sp. que es una bacteria Gram positiva, cuya pared celular es más compleja para lisar. Mientras que Velezmoro et al. (2011) utilizaron el kit Axy Prep Bacterial Genomic DNA Miniprep kit, para extraer el ADN de cepas de Bacillus sp.

Addison et al. (2007) aislaron un diazótrofo similar a miembros del género Novosphingobium. También se le ha detectado la presencia del Gen nif $H$ y la capacidad de reducción del acetileno. Estos resultados les permitieron proponer una especie nueva de Novosphingobium nitrogenifigens sp. Nov. Los géneros Sphingomonas, Sphingobium y Novosphingobium se está convirtiendo cada vez más de interés en microbiología industrial debido a diversos compuestos que pueden ser degradados por estos géneros como: hidrocarburos aromáticos policíclicos, fenoles clorados, herbicidas y una variedad de benzofuranos (Ederer et al., 1997; Khan et al., 1996; Yrjala et al., 1998; Zylstra \& Kim , 1997).

Chelius \& Triplett (2000) aislaron también cepas de Klebsiella pneumoniae, y encontraron que pueden colonizar las raíces de plantas de arroz y estimular la formación de pelos absorbentes, mencionan que esta bacteria es considerada como un microorganismo endofítico capaz de fijar nitrógeno en el interior de la raíz.

La secuencia parcial del gen del ARN ribosomal $16 \mathrm{~S}$ para las cepas bacterianas $11 \mathrm{D}, 13 \mathrm{C}$ y $30 \mathrm{D}$ están estrechamente relacionadas a Azotobacter vinelandii. Estas bacterias fueron capaces de incrementar significativamente el porcentaje de germinación de semillas de alfalfa, pero no produjeron halo visible de solubilización de fosfato tricálcico, ni presentaron la capacidad de producir AIA. Asimismo, la cepa 17C Bacillus sp. no produjo AIA ni solubilizó fósforo. Sin embargo, Calvo et al. (2010) encontraron un $81 \%$ y $58 \%$ de cepas de Bacillus que produjeron AIA y fueron capaces de solubilizar fosfato, respectivamente.

\section{Conclusiones.}

1. Se aislaron 104 cepas de bacterias diazotróficas nativas de la rizósfera del olivo en la zona de La Yarada-Tacna y se seleccionaron las 20 mejores de acuerdo a sus características bioquímicas $\mathrm{y}$ fisiológicas.

2. Las bacterias diazotróficas nativas aisladas tienen una correlación con la materia orgánica, fósforo, el $\mathrm{pH}$ del suelo, tipo de riego y profundidad de la raíz, a su vez se observa una mayor concentración de materia orgánica a mayor profundidad del suelo.

3. De 104 cepas aisladas de la rizósfera del olivo, el $58.65 \%$ produjo ácido indol acético, el 25.96\% solubilizó fosfato tricálcico y el $45.2 \%$ incrementaron significativamente la germinación de las semillas de alfalfa.

4. El incremento de la germinación por diferentes cepas estudiadas en este trabajo, junto con la producción de ácido indolacético y solubilización de fosfatos, indica su potencial como inoculantes microbianos para el cultivo de olivo.

5. Para la identificación molecular de bacterias diazotróficas, se trabajaron con 4 bases de datos: Blast, Ribosonal Database, Bibi Database y Ez Taxon, se consideró lo reportado por Ez Taxon e identificadas hasta especies las que tuvieron más del 99\% de similitud.

6. El análisis molecular de las cepas seleccionadas, permitió identificar hasta especie un 55\% (11cepas) y hasta género un $45 \%$ (9 cepas).

7. Del total de cepas identificadas molecularmente predominó la familia Sphingomonadaceae con un $50 \%$, lo que indicaría la efectividad de esta familia como rizobacterias promotoras del crecimiento vegetal en el cultivo del olivo.

8. Las especies identificadas molecularmente fueron: Novosphingobium scionense, Novosphingobium resinovorum, Burkholderia metallica, Rhizobium massiliae, Klebsiella pneumoniae subsp. rhinoscleromatis, Azotobacter vinelandii, Erwinia tasmaniensis y Raoultella planticola. 


\section{Agradecimientos.}

Al FINCyT-PITEI 2010. A la empresa Biondi y Cía. de Tacna S.A.C. y al Laboratorio CITELAB del Módulo de Servicios Tacna CITE Agroindustrial.

\section{Literatura citada.}

Addison S., Foote S., Nicola R. \& Gareth L. 2007. Novosphingobium nitrogenifigens sp. nov., a polyhydroxyalkanoate-accumulating diazotroph isolated from a New Zealand pulp and paper wastewater. International Journal of Systematic and Evolutionary Microbiology. 57: 2467-2471.

Ahmad F., Ahmad I. \& Khan M. 2005. Indole acetic acid production by the indigenous isolates of Azotobacter and fluorescent Pseudomonas in the presence and absence of tryptophan. Turkey Journal of Biology. 29: 29-34.

Calvo P., Reymundo L. \& Zúñiga D. 2008. Estudio de las poblaciones microbianas de la rizósfera del cultivo de papa (Solanum tuberosum) en zonas altoandinas. Ecología Aplicada. 7: 141-148.

Calvo P., Ormeño E., Martínez E. \& Zúñiga D. 2010. Characterization of Bacillus isolates of potato rhizosphere from andean soils of Peru and their potential PGPR characteristics. Brazilian Journal of Microbiology. 41: 899-906.

Celis L. \& Gallardo I. 2008. Estandarización de métodos de detección para promotores de crecimiento vegetal (ácido indol acético y giberelinas) en cultivos microbianos. Tesis Microbiólogo Agrícola y Veterinario. PUJ.

Chelius M. \& Triplett E. 2000. Immunolocalization of dinitrogenase reductase produced by Klebsiella pneumoniae in association with Zea mays L. Applied and Environmental Microbiology. 66: 783-787.

Ederer M., Crawford R., Herwig R. \& Orser C. 1997. PCP degradation is mediated by closely related strains of the genus Sphingomonas. Molecular Ecology. 6: 39-49.

Frioni L. 1999. Procesos microbianos. Editorial Plant and Soil. Córdova-Argentina.

García, F. \& T. Herraiz. 1987. Production of 3-indoleacetic acid and 3- indolelactic acid in Azotobacter vinelandii cultures supplemented with tryptophan. Applied Microbiology and Biotechnology. 25: 502-506.

Jiménez D. 2007. Caracterización molecular de cepas nativas colombianas de Azotobacter spp. mediante el análisis de restricción de DNA ribosomal 16S. Tesis Microbiólogo Industrial. PUJ.

Khan A., Wang R., Cao W., Franklin W. \& Cerniglia C. 1996. Reclassification of a polycyclic aromatic hydrocarbon-metabolizing bacterium, Beijerinckia sp. strain B1, as Sphingomonas yanoikuyae by fatty acid analysis, protein pattern analysis, DNA-DNA hybridization, and $16 \mathrm{~S}$ ribosomal DNA sequencing. International Journal of Systematic Bacteriology. 46: 466-469.

Kim O. S., Cho, Y. J., Lee K., Yoon S.H., Kim M., Na H., Park S.C., Jeon Y.S., Lee J.H., Yi H., Won S., Chun J. 2012. Introducing Ez Taxon-e: a prokaryotic 16S rRNA gene sequence database with phylotypes that represent uncultured species. International Journal of Systematic and Evolutionary Microbiology. 62: 716-721.

Mc Farland J. 1907. Nephelometer. JAMA 14: 1176-1178.

Mignard S \& Flandrois J. 2006. 16S rRNA sequencing in routine bacterial identification: A 30-month experiment. Journal of Microbiological Methods. 67: 574-581.
Mrkovacki N. \& Milic V. 2001. Use of Azotobacter chroococcum as potentially useful in agricultural application. Annals of Microbiology. 51: 145-158.

Myers E. W. \& Miller W. 1988. Optimal alignments in linear space. Computer Applications in the Biosciences. 4: $11-17$.

Naik P. \& Sakthivel N. 2006. Funtional characterization of a novel hydrocarbonoclastic Pseudomonas sp. strain PUP6 with plant-growth-promoting traits and antifungal potential. Research in Microbiology. 157: 538-546.

Nautiyal C. S. 1999. An efficient microbiological growth medium for screening phosphate solubilizing microorganims. FEMS Microbiology Letters. 170: 265270.

Navas J. 2010. La aceituna en el Perú. PROMPEX Perú y ANPEAP.

http://www.monografias.com/trabajos46/aceitunaperu/aceituna-peru2.shtml.

Obando D.M., Burgos L.B., Rivera D.M., Rubiano M.F., Diván D.L. \& Bonilla R.B. 2010. Caracterización de bacterias diazotróficas asimbióticas asociadas al eucalipto (Eucalyptus sp.) en Codazzi, César (Colombia). Acta Biológica Colombiana. 15: 107-120.

Ogata K., Arellano C. \& Zúñiga D. 2008. Efecto de diferentes bacterias aisladas de rizósfera de Caesalpina spinosa en la germinación de diferentes especies vegetales cultivados. Zonas Áridas. 12: 137-153.

Ogata K. \& Zúñiga D. 2005. Estudio de la microflora de la rizósfera de Caesalpina spinosa en la provincia de Huánuco. Zonas Áridas. 12: 191-208.

Olalde P. \& Aguilera L. 1998. Microorganismos y Biodiversidad. Terra. 16: 289-292.

Rico M. 2009. Capacidad promotora de crecimiento vegetal por bacterias del género Azotobacter y Actinomicetos aislados de cultivos de Solanum tuberosum Linnaeus, 1753 (Papa) cultivados en zonas altoandinas del Perú. Tesis Biólogo. UNMSM.

Stewart W. 1991. The important to sustainable agricultura of biodiversity among invertebrates and microorganisms. In: D. L. Hawksworth (ed) The biodiversity of microorganisms and invertebrates: Its role in sustainable agricultura: 3-5. Redwood Press, Melksham, UK.

Tsavkelova E., Klimova S., Cherdyntseva T. \& Netrusov A. 2006. Microbial producers of plant growth stimulators and their practical use: A Review. Applied Biochemistry and Microbiology. 42: 117-126.

Velezmoro C., Ramos E., García C. \& Zúñiga D. 2011. Genotypic identification of Bacillus sp. isolated from canned white asparagus (Asparagus officinalis) during the production/ processing chain in northern Peru. Annals of Microbiology. 62: 1207-1217.

Vessey J.K. 2003. Plant growth promoting rhizobacteria as biofertilizers. Plant Soil. 255: 571-586.

Yrjala K., Suomalainen S., Suhonen E., Kilpi S., Paulin L. \& Romantschuk M. 1998. Characterization and reclassification of an aromatic- and chloroaromaticdegrading Pseudomonas sp., strain HV3, as Sphingomonas sp. HV3. International Journal of Systematic Bacteriology. 48: 1057-1062.

Zapater J. 1975. Evaluación en el maíz del coeficiente rizósfera-suelo (R/S) referidos a bacterias libres fijadoras de $\mathrm{N}_{2}$. Anales Científicos de la UNALM. 13: 45-57. 
Zylstra G. \& Kim E. 1997. Aromatic hydrocarbon degradation by Sphingomonas yanoikuyae B1. Journal of Industrial Microbiology and Biotechnology. 19: 408414.
Zúñiga D. 2012. Manual de Microbiología Agrícola: Rhizobium, PGPRs, Indicadores de Fertilidad e Inocuidad. Ed. Olaya M. Universidad Nacional Agraria La Molina. Lima-Perú.

\section{ANEXO}

Tablas citadas en el texto

Tabla 1. Recuento de bacterias diazotróficas (método del NMP)

\begin{tabular}{|c|c|c|c|c|}
\hline $\begin{array}{c}\mathrm{N}^{0} \text { de } \\
\text { muestra de } \\
\text { suelo }\end{array}$ & Código & $\begin{array}{l}\text { Tipo } \\
\text { de } \\
\text { riego }\end{array}$ & $\begin{array}{l}\text { Profundidad } \\
\text { de la raíz }\end{array}$ & NMP/g \\
\hline 1 & S2C3 & G & $60 \mathrm{~cm}$ & $2.4 \times 10^{3}$ \\
\hline 2 & S3C2 & G & $60 \mathrm{~cm}$ & $>1.1 \times 10^{4}$ \\
\hline 3 & S4C1 & G & $60 \mathrm{~cm}$ & $4.6 \times 10^{3}$ \\
\hline 4 & S4C5 & G & $60 \mathrm{~cm}$ & $>1.1 \times 10^{4}$ \\
\hline 5 & S6C1 & G & $60 \mathrm{~cm}$ & $4.6 \times 10^{3}$ \\
\hline 6 & S6C5 & G & $60 \mathrm{~cm}$ & $4.6 \times 10^{3}$ \\
\hline 7 & S7C4 & G & $60 \mathrm{~cm}$ & $4.6 \times 10^{3}$ \\
\hline 8 & S8C3 & G & $60 \mathrm{~cm}$ & $>1.1 \times 10^{4}$ \\
\hline 9 & S9C2 & G & $60 \mathrm{~cm}$ & $4.6 \times 10^{3}$ \\
\hline 10 & S10C1 & G & $60 \mathrm{~cm}$ & $>1.1 \times 10^{4}$ \\
\hline 11 & S10C5 & G & $60 \mathrm{~cm}$ & $1.5 \times 10^{3}$ \\
\hline 12 & S11C4 & G & $60 \mathrm{~cm}$ & 23 \\
\hline 13 & S12C3 & G & $60 \mathrm{~cm}$ & 40 \\
\hline 14 & S13C2 & G & $60 \mathrm{~cm}$ & $9.3 \times 10^{2}$ \\
\hline 15 & S14C1 & M & $30 \mathrm{~cm}$ & 23 \\
\hline 16 & S15C1 & M & $30 \mathrm{~cm}$ & $1.5 \times 10^{3}$ \\
\hline 17 & S15C5 & M & $30 \mathrm{~cm}$ & 23 \\
\hline 18 & S16C4 & M & $30 \mathrm{~cm}$ & $7.5 \times 10^{2}$ \\
\hline 19 & S17C3 & M & $30 \mathrm{~cm}$ & $1.5 \times 10^{2}$ \\
\hline 20 & S18C2 & M & $30 \mathrm{~cm}$ & $2.3 \times 10^{2}$ \\
\hline 21 & S19C1 & M & $30 \mathrm{~cm}$ & $2.3 \times 10^{2}$ \\
\hline 22 & S19C5 & M & $30 \mathrm{~cm}$ & $2.3 \times 10^{2}$ \\
\hline 23 & S20C4 & M & $30 \mathrm{~cm}$ & $>1.1 \times 10^{4}$ \\
\hline 24 & S21C3 & M & $30 \mathrm{~cm}$ & $7.5 \times 10^{2}$ \\
\hline 25 & S22C2 & M & $30 \mathrm{~cm}$ & 90 \\
\hline 26 & S23C1 & M & $30 \mathrm{~cm}$ & $1.5 \times 10^{3}$ \\
\hline 27 & S23C5 & M & $30 \mathrm{~cm}$ & $1.1 \times 10^{4}$ \\
\hline 28 & S24C4 & M & $30 \mathrm{~cm}$ & 40 \\
\hline 29 & S25C3 & M & $30 \mathrm{~cm}$ & $2.4 \times 10^{3}$ \\
\hline 30 & S26C2 & M & $30 \mathrm{~cm}$ & $2.3 \times 10^{2}$ \\
\hline
\end{tabular}


Tabla 2: Matriz de correlación de Pearson entre las variables fisicoquímicas, enumeración de bacterias diazotróficas, profundidad de la raíz y el tipo de riego.

\begin{tabular}{|c|c|c|c|c|c|c|c|c|c|c|c|c|c|}
\hline & $\begin{array}{l}\text { Tipo } \\
\text { riego }\end{array}$ & $\begin{array}{l}\text { Prof. } \\
\text { raíz } \\
(\mathrm{cm})\end{array}$ & $\mathrm{NMP} / \mathrm{g}$ & $\mathrm{pH}$ & $\begin{array}{c}\text { M O } \\
(\%)\end{array}$ & $\begin{array}{c}\mathrm{N} \\
(\%)\end{array}$ & $\begin{array}{c}\mathrm{P} \\
(\mathrm{ppm})\end{array}$ & $\begin{array}{c}\mathrm{K} \\
(\mathrm{ppm})\end{array}$ & $\begin{array}{c}\mathrm{CE} \\
(\mathrm{dS} / \mathrm{m})\end{array}$ & $\begin{array}{c}\mathrm{HCO}_{3} \\
\text { (meq } \\
/ \mathrm{L} \text { ) }\end{array}$ & $\begin{array}{c}\text { Arena } \\
(\%)\end{array}$ & $\begin{array}{c}\text { Limo } \\
(\%)\end{array}$ & $\begin{array}{c}\text { Arcilla } \\
(\%)\end{array}$ \\
\hline Tipo riego & 1.00 & & & & & & & & & & & & \\
\hline Prof. raíz (cm) & $\begin{array}{l}-1.00 \\
0.00 *\end{array}$ & 1.00 & & & & & & & & & & & \\
\hline $\mathrm{NMP} / \mathrm{g}$ & $\begin{array}{l}-0.43 \\
0.02 *\end{array}$ & $\begin{array}{c}0.43 \\
0.02 *\end{array}$ & 1.00 & & & & & & & & & & \\
\hline $\mathrm{pH}$ & $\begin{array}{l}-0.15 \\
0.43^{*}\end{array}$ & $\begin{array}{c}0.15 \\
0.43^{*}\end{array}$ & $\begin{array}{l}-0.48 \\
0.01^{*}\end{array}$ & 1.00 & & & & & & & & & \\
\hline M O (\%) & $\begin{array}{l}-0.49 \\
0.01 *\end{array}$ & $\begin{array}{c}0.49 \\
0.01 *\end{array}$ & $\begin{array}{c}0.46 \\
0.01 *\end{array}$ & $\begin{array}{c}0.02 \\
0.92 *\end{array}$ & 1.00 & & & & & & & & \\
\hline N (\%) & $\begin{array}{l}-0.12 \\
0.52 *\end{array}$ & $\begin{array}{c}0.12 \\
0.52 *\end{array}$ & $\begin{array}{c}0.22 \\
0.23 *\end{array}$ & $\begin{array}{c}0.15 \\
0.43^{*}\end{array}$ & $\begin{array}{c}0.35 \\
0.06^{*}\end{array}$ & 1.00 & & & & & & & \\
\hline $\mathrm{P}(\mathrm{ppm})$ & $\begin{array}{l}-0.18 \\
0.35^{*}\end{array}$ & $\begin{array}{c}0.18 \\
0.35^{*}\end{array}$ & $\begin{array}{c}0.53 \\
0.00 *\end{array}$ & $\begin{array}{l}-0.25 \\
0.19 *\end{array}$ & $\begin{array}{c}0.66 \\
0.00 *\end{array}$ & $\begin{array}{c}0.18 \\
0.33^{*}\end{array}$ & 1.00 & & & & & & \\
\hline $\mathrm{K}(\mathrm{ppm})$ & $\begin{array}{l}-0.06 \\
0.77^{*}\end{array}$ & $\begin{array}{c}0.06 \\
0.77^{*}\end{array}$ & $\begin{array}{l}-0.35 \\
0.06^{*}\end{array}$ & $\begin{array}{c}0.26 \\
0.16^{*}\end{array}$ & $\begin{array}{l}-0.11 \\
0.56^{*}\end{array}$ & $\begin{array}{l}-0.29 \\
0.12 *\end{array}$ & $\begin{array}{l}-0.33 \\
0.07^{*}\end{array}$ & 1.00 & & & & & \\
\hline $\mathrm{CE}(\mathrm{dS} / \mathrm{m})$ & $\begin{array}{l}-0.19 \\
0.32 *\end{array}$ & $\begin{array}{c}0.19 \\
0.32 *\end{array}$ & $\begin{array}{c}0.13 \\
0.49 *\end{array}$ & $\begin{array}{l}-0.22 \\
0.24 *\end{array}$ & $\begin{array}{c}0.20 \\
0.28^{*}\end{array}$ & $\begin{array}{l}-0.04 \\
0.84 *\end{array}$ & $\begin{array}{c}0.14 \\
0.46^{*}\end{array}$ & $\begin{array}{c}0.10 \\
0.60^{*}\end{array}$ & 1.00 & & & & \\
\hline $\mathrm{HCO}_{3}(\mathrm{meq} / \mathrm{L})$ & -0.02 & 0.02 & 0.20 & 0.01 & 0.27 & -0.03 & 0.26 & 0.23 & 0.30 & 1.00 & & & \\
\hline Arena (\%) & $\begin{array}{c}0.93^{*} \\
0.38 \\
0.04 *\end{array}$ & $\begin{array}{c}0.93^{*} \\
-0.38 \\
0.04 *\end{array}$ & $\begin{array}{l}0.30^{*} \\
-0.21 \\
0.27 *\end{array}$ & $\begin{array}{c}0.96 * \\
-0.05 \\
0.77 *\end{array}$ & $\begin{array}{c}0.15^{*} \\
-0.41 \\
0.03^{*}\end{array}$ & $\begin{array}{c}0.88^{*} \\
-0.14 \\
0.47^{*}\end{array}$ & $\begin{array}{l}0.16^{*} \\
-0.35 \\
0.06^{*}\end{array}$ & $\begin{array}{c}0.22 * \\
0.04 \\
0.84 *\end{array}$ & $\begin{array}{c}0.11^{*} \\
-0.20 \\
0.28^{*}\end{array}$ & $\begin{array}{l}-0.12 \\
0.54^{*}\end{array}$ & 1.00 & & \\
\hline Limo (\%) & $\begin{array}{l}-0.33 \\
0.08^{*}\end{array}$ & $\begin{array}{c}0.33 \\
0.08 *\end{array}$ & $\begin{array}{l}-0.19 \\
0.32 *\end{array}$ & $\begin{array}{l}-0.03 \\
0.89 *\end{array}$ & $\begin{array}{l}-0.10 \\
0.58^{*}\end{array}$ & $\begin{array}{l}-0.27 \\
0.15^{*}\end{array}$ & $\begin{array}{l}-0.11 \\
0.55^{*}\end{array}$ & $\begin{array}{c}0.37 \\
0.04 *\end{array}$ & $\begin{array}{c}0.03 \\
0.87 *\end{array}$ & $\begin{array}{l}-0.13 \\
0.49 *\end{array}$ & $\begin{array}{l}-0.33 \\
0.07^{*}\end{array}$ & 1.00 & \\
\hline Arcilla (\%) & $\begin{array}{l}-0.09 \\
0.65 *\end{array}$ & $\begin{array}{c}0.09 \\
0.65^{*}\end{array}$ & $\begin{array}{c}0.34 \\
0.06^{*}\end{array}$ & $\begin{array}{c}0.07 \\
0.71 *\end{array}$ & $\begin{array}{c}0.46 \\
0.01^{*}\end{array}$ & $\begin{array}{c}0.35 \\
0.06 *\end{array}$ & $\begin{array}{c}0.42 \\
0.02 *\end{array}$ & $\begin{array}{l}-0.34 \\
0.07^{*}\end{array}$ & $\begin{array}{c}0.16 \\
0.40^{*}\end{array}$ & $\begin{array}{c}0.21 \\
0.26^{*}\end{array}$ & $\begin{array}{l}-0.65 \\
0.00^{*}\end{array}$ & $\begin{array}{l}-0.50 \\
0.00 *\end{array}$ & 1.00 \\
\hline
\end{tabular}

* Valor P que prueba la significancia estadística de las correlaciones estimadas. Valores $\mathrm{P}<0.05$ indican correlaciones significativas (color gris), con un nivel de confianza del 95.0\%.

Fuente: Correlaciones obtenidas mediante análisis estadístico con software.

El rango de estos coeficientes de correlación va de -1 a +1 y miden la fuerza de la relación lineal entre las variables. 
Tabla 3. Caracterización fenotípica de las 104 cepas aisladas de la rizósfera del olivo en La Yarada-Tacna

\begin{tabular}{|c|c|c|c|c|c|c|c|c|c|c|c|c|c|}
\hline \multirow{13}{*}{ 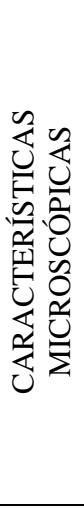 } & \multirow[t]{2}{*}{ Etiqueta } & \multicolumn{11}{|c|}{ CARACTERÍSTICAS MACROSCÓPICAS } & \multirow{2}{*}{$\begin{array}{c}\text { Total } \\
\text { de } \\
\text { cepas }\end{array}$} \\
\hline & & 1 & 2 & 3 & 4 & 5 & 6 & 7 & 8 & 9 & 10 & 11 & \\
\hline & 1 & 23 & 0 & 0 & 0 & 0 & 0 & 0 & 0 & 0 & 0 & 0 & 23 \\
\hline & 2 & 0 & 13 & 7 & 1 & 1 & 0 & 0 & 1 & 0 & 0 & 0 & 23 \\
\hline & 3 & 1 & 18 & 2 & 0 & 0 & 4 & 1 & 1 & 0 & 1 & 0 & 28 \\
\hline & 4 & 1 & 7 & 0 & 0 & 0 & 1 & 0 & 0 & 0 & 0 & 0 & 9 \\
\hline & 5 & 0 & 9 & 4 & 0 & 0 & 0 & 0 & 0 & 0 & 0 & 0 & 13 \\
\hline & 6 & 2 & 0 & 0 & 0 & 0 & 0 & 0 & 0 & 0 & 0 & 0 & 2 \\
\hline & 7 & 0 & 0 & 0 & 0 & 0 & 0 & 0 & 0 & 0 & 0 & 1 & 1 \\
\hline & 8 & 0 & 1 & 0 & 0 & 0 & 0 & 0 & 0 & 0 & 0 & 0 & 1 \\
\hline & 9 & 0 & 0 & 0 & 0 & 0 & 0 & 0 & 1 & 0 & 0 & 0 & 1 \\
\hline & 10 & 0 & 1 & 0 & 0 & 0 & 0 & 0 & 1 & 0 & 0 & 0 & 2 \\
\hline & 11 & 0 & 0 & 0 & 0 & 0 & 0 & 0 & 0 & 1 & 0 & 0 & 1 \\
\hline Tota & e cepas & 27 & 49 & 13 & 1 & 1 & 5 & 1 & 4 & 1 & 1 & 1 & 104 \\
\hline
\end{tabular}

El color gris indica la combinación de las características más comunes que presentaron las cepas aisladas.

Donde:

Características microscópicas: 1: Bacilo largo y ovoide, 2: Cocobacilos, 3: Bacilos, 4: Bacilos elipsoidales, 5: Bacilos pequeños, 6: Cocoides, 7: Bacilos grandes, 8: Bacilos largos, 9: Bacilos en pares, 10: Cocos, 11: Bacilos dispuestos en cadena.

Características macroscópicas: 1: Circular, regular, elevada, lisa, crema brillante; 2: Circular, regular, elevada, lisa, transparente brillante; 3: Ovalada, regular, elevada, lisa, transparente brillante; 4: Ovalada, irregular, elevada, lisa, transparente brillante; 5: Circular, irregular, elevada, lisa, transparente brillante; 6: Circular, regular, elevada, lisa, blanco humo; 7: Irregular, irregular, elevada, lisa, transparente brillante; 8: Irregular, regular, elevada, lisa, transparente brillante; 9: Circular, regular, elevada, lisa, blanco humo con halo; 10: Circular, regular, elevada, lisa, transparente brillante, con halo; 11: Circular, regular, elevada, lisa, crema opaca, colonias con halo. 
Tabla 4. Selección de 20 cepas mediante la valoración de las características fenotípicas, bioquímicas y fisiológicas usando el análisis de ponderados.

\begin{tabular}{|c|c|c|c|c|c|c|c|c|}
\hline $\begin{array}{l}\mathrm{N}^{\circ} \text { de } \\
\text { orden }\end{array}$ & Сepa & Género/especie & Caract. Microscópicas & $\begin{array}{l}\text { AIA } \\
(\mu \mathrm{g} / \mathrm{ml})\end{array}$ & $\begin{array}{l}\text { ASP } \\
\left(\mathrm{cm}^{2}\right)\end{array}$ & $\begin{array}{c}\text { \% de } \\
\text { geminación }\end{array}$ & $\begin{array}{l}\text { Crecimiento } \\
\text { en MMSN }\end{array}$ & $\begin{array}{c}\text { Ponderado } \\
\%\end{array}$ \\
\hline 1 & $11 \mathrm{~A}$ & Sphingobium scionense & Gram negativo, bacilos elipsoidales & 46.47 & 0 & 43.53 & 3 & 69.02 \\
\hline 2 & 7B & Burkholderia metallica & Gram negativo, bacilos & 0 & 2.43 & 41.84 & 2 & 57.81 \\
\hline 3 & 3B & Novosphingobium sp. & Gram negativo, bacilos elipsoidales & 0 & 0 & 41.54 & 3 & 57.19 \\
\hline 4 & $9 \mathrm{~K}$ & Sphingobium scionense & Gram negativo, bacilos elipsoidales & 34.4 & 0 & 44.23 & 2 & 56.75 \\
\hline 5 & $26 B$ & Sphingobium scionense & Gram negativo, bacilos elipsoidales & 37.04 & 0 & 27.42 & 3 & 56.34 \\
\hline 6 & $11 \mathrm{I}$ & Novosphingobium sp. & Gram negativo, bacilos largos & 25.63 & 0 & 43.68 & 2 & 54.40 \\
\hline 7 & $7 \mathrm{~A}$ & Rhizobium massiliae & Gram negativo, bacilos pequeños & 37.78 & 0 & 39.47 & 2 & 54.40 \\
\hline 8 & $14 \mathrm{~A}$ & Erwinia tasmaniensis & Gram negativo, bacilos pequeños & 2.42 & 5.84 & 42.37 & 0 & 53.27 \\
\hline 9 & $16 \mathrm{~B}$ & Novosphingobium resinovorum & Gram negativo, bacilos elipsoidales & 0 & 0 & 34.85 & 3 & 52.81 \\
\hline 10 & $13 \mathrm{C}$ & Azotobacter sp. & Gram negativo, bacilo largo ovoide & 0 & 0 & 34.43 & 3 & 52.54 \\
\hline 11 & $30 \mathrm{D}$ & Azotobacter sp. & Gram negativo, bacilo largo ovoide & 0 & 0 & 34.29 & 3 & 52.44 \\
\hline 12 & $9 \mathrm{~F}$ & Novosphingobium sp. & Gram negativo, bacilos pequeños & 0 & 0 & 33.33 & 3 & 51.82 \\
\hline 13 & $12 \mathrm{G}$ & Novosphingobium sp. & Gram negativo, bacilos elipsoidales & 7.52 & 0 & 45.45 & 2 & 51.46 \\
\hline 14 & $17 \mathrm{C}$ & Bacillus sp. & $\begin{array}{l}\text { Gram positivo, bacilos dispuestos } \\
\text { en cadenas }\end{array}$ & 0 & 0 & 32.22 & 3 & 51.09 \\
\hline 15 & $14 \mathrm{~B}$ & Erwinia tasmaniensis & Gram negativa, bacilos pequeños & 10.66 & 2.82 & 24.56 & 2 & 50.56 \\
\hline 16 & $3 \mathrm{~A}$ & Novosphingobium sp. & Gram negativo, bacilos elipsoidales & 0 & 0 & 45.83 & 2 & 50.00 \\
\hline 17 & $27 \mathrm{~F}$ & Novosphingobium sp. & Gram negativo, bacilo & 0 & 0 & 42.68 & 2 & 47.94 \\
\hline 18 & $11 \mathrm{D}$ & Azotobacter vinelandii & Gram negativo, bacilo largo ovoide & 0 & 0 & 41.94 & 2 & 47.45 \\
\hline 19 & $18 \mathrm{~A}$ & Raoultella planticola & Gram negativo, bacilos pequeños & 28.33 & 0.42 & 28.57 & 2 & 46.93 \\
\hline 20 & $5 \mathrm{~A}$ & $\begin{array}{l}\text { Klebsiella pneumoniae } \\
\text { subsp. rhinoscleromatis }\end{array}$ & Gram negativo, bacilos pequeños & 35.60 & 0.31 & 26.47 & 2 & 46.71 \\
\hline
\end{tabular}

* Crecimiento en el MMSN durante $48 \mathrm{~h}$ a $28{ }^{\circ} \mathrm{C}$. Equivalencia a la Escala turbidimétrica de Mc Farland:

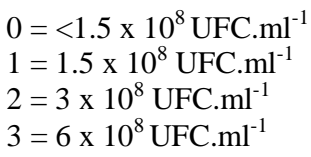

$30 \%$ 
Tabla 5. Efecto de la inoculación de bacterias diazotróficas nativas en el porcentaje de germinación de alfalfa (Medicago sativa) a las 48 h de germinación.

\begin{tabular}{|c|c|c|c|c|c|c|c|c|}
\hline Código & $\begin{array}{c}\mathrm{G}^{\mathrm{a}} \\
(\%)\end{array}$ & I (\%) & Código & $\begin{array}{c}\mathrm{G}^{\mathrm{a}} \\
(\%)\end{array}$ & I (\%) & Código & $\begin{array}{c}\mathrm{G}^{\mathrm{a}} \\
(\%)\end{array}$ & $\begin{array}{c}\text { I } \\
(\%)\end{array}$ \\
\hline $1 \mathrm{~A}^{* *}$ & $17 \%$ & - & $11 F^{*}$ & $36 \%$ & $82 \%$ & $18 C^{* *}$ & $16 \%$ & - \\
\hline $1 \mathrm{~B} * * *$ & $4 \%$ & - & $11 \mathrm{G}^{* * *}$ & $12 \%$ & - & $19 A^{* *}$ & $25 \%$ & - \\
\hline $1 \mathrm{C}^{* *}$ & $25 \%$ & - & $11 \mathrm{H}^{* *}$ & $18 \%$ & - & $19 B *$ & $32 \%$ & $61 \%$ \\
\hline $2 \mathrm{~A}^{*}$ & $30 \%$ & $53 \%$ & $11 I^{*}$ & $44 \%$ & $118 \%$ & $19 C^{*}$ & $27 \%$ & $37 \%$ \\
\hline $2 \mathrm{~B}^{*}$ & $39 \%$ & $96 \%$ & $12 \mathrm{~A}^{* *}$ & $18 \%$ & - & $19 D^{*}$ & $40 \%$ & $98 \%$ \\
\hline $3 \mathrm{~A}^{*}$ & $46 \%$ & $129 \%$ & $12 \mathrm{~B}^{* * *}$ & $24 \%$ & - & $19 E^{* *}$ & $21 \%$ & - \\
\hline $3 \mathrm{~B}^{*}$ & $42 \%$ & $108 \%$ & $12 \mathrm{C}^{* *}$ & $22 \%$ & - & $20 A^{*}$ & $30 \%$ & $50 \%$ \\
\hline $4 \mathrm{~A}^{* * *}$ & $13 \%$ & - & $12 \mathrm{D} * *$ & $19 \%$ & - & $20 B^{*}$ & $36 \%$ & $80 \%$ \\
\hline $4 \mathrm{~B}^{*}$ & $36 \%$ & $79 \%$ & $12 \mathrm{E}^{*}$ & $29 \%$ & $44 \%$ & $21 A^{* *}$ & $26 \%$ & - \\
\hline $5 \mathrm{~A}^{* *}$ & $26 \%$ & - & $12 \mathrm{~F}^{*}$ & $34 \%$ & $72 \%$ & $21 B * *$ & $16 \%$ & - \\
\hline $5 \mathrm{~B} * * *$ & $14 \%$ & - & $12 \mathrm{G}^{*}$ & $45 \%$ & $127 \%$ & $22 \mathrm{~A} *$ & $31 \%$ & $56 \%$ \\
\hline $5 C^{* *}$ & $22 \%$ & - & $13 \mathrm{~A}^{* * *}$ & $11 \%$ & - & $22 B *$ & $36 \%$ & $82 \%$ \\
\hline $5 D^{*}$ & $30 \%$ & $49 \%$ & $13 \mathrm{~B} * * *$ & $14 \%$ & - & $23 A^{*}$ & $28 \%$ & $40 \%$ \\
\hline 7A* & $39 \%$ & $97 \%$ & $13 C^{*}$ & $34 \%$ & $72 \%$ & $23 \mathrm{~B} * *$ & $29 \%$ & - \\
\hline $7 B^{*}$ & $42 \%$ & $109 \%$ & $13 D^{*}$ & $40 \%$ & $102 \%$ & $23 C^{*}$ & $29 \%$ & $45 \%$ \\
\hline $7 C^{*}$ & $44 \%$ & $119 \%$ & $13 \mathrm{E}^{* *}$ & $19 \%$ & - & $24 A^{*}$ & $43 \%$ & $\begin{array}{c}114 \\
\%\end{array}$ \\
\hline 7D* & $43 \%$ & $116 \%$ & $13 \mathrm{~F}^{* * * *}$ & $9 \%$ & - & $24 \mathrm{~B} * *$ & $24 \%$ & - \\
\hline $8 A^{* *}$ & $21 \%$ & - & $14 \mathrm{~A}^{*}$ & $42 \%$ & $112 \%$ & $25 B * * *$ & $9 \%$ & - \\
\hline $8 B^{*}$ & $43 \%$ & $117 \%$ & $14 \mathrm{~B}^{* * *}$ & $25 \%$ & - & $25 \mathrm{D} * *$ & $17 \%$ & - \\
\hline $8 C^{* *}$ & $16 \%$ & - & $14 C^{* *}$ & $21 \%$ & - & $26 \mathrm{~A}^{* * *}$ & $12 \%$ & - \\
\hline $9 A^{* *}$ & $23 \%$ & - & $14 \mathrm{~F}^{* *}$ & $19 \%$ & - & $26 B * *$ & $27 \%$ & - \\
\hline $9 B * *$ & $13 \%$ & - & $15 A^{* *}$ & $26 \%$ & - & $27 \mathrm{~A}^{* * *}$ & $8 \%$ & - \\
\hline $9 C^{* *}$ & $28 \%$ & - & $15 C^{* *}$ & $24 \%$ & & $27 \mathrm{~B} * *$ & $26 \%$ & - \\
\hline $9 D^{*}$ & $33 \%$ & $64 \%$ & $15 E^{*}$ & $31 \%$ & $56 \%$ & $27 C^{* *}$ & $21 \%$ & - \\
\hline $9 \mathrm{E}^{* *}$ & $18 \%$ & - & $15 F^{*}$ & $35 \%$ & $75 \%$ & $27 D^{* *}$ & $27 \%$ & - \\
\hline $9 \mathrm{~F}^{*}$ & $33 \%$ & $67 \%$ & $16 A^{*}$ & $29 \%$ & $45 \%$ & $27 F^{*}$ & $43 \%$ & $\begin{array}{c}113 \\
\%\end{array}$ \\
\hline $9 \mathrm{G}^{*}$ & $27 \%$ & $34 \%$ & $16 B^{*}$ & $35 \%$ & $74 \%$ & $28 A^{* *}$ & $23 \%$ & - \\
\hline $9 \mathrm{H}^{*}$ & $41 \%$ & $106 \%$ & $16 C^{* * *}$ & $12 \%$ & - & $29 A^{* *}$ & $25 \%$ & - \\
\hline $9 \mathrm{~J} * *$ & $20 \%$ & - & $17 A^{*}$ & $44 \%$ & $122 \%$ & $29 B * *$ & $23 \%$ & - \\
\hline $9 \mathrm{~K}^{*}$ & $44 \%$ & $121 \%$ & $17 \mathrm{~B} * * *$ & $13 \%$ & - & $29 C^{* *}$ & $26 \%$ & - \\
\hline $9 \mathrm{~L}^{* *}$ & $28 \%$ & - & $17 C^{*}$ & $32 \%$ & $61 \%$ & 30 A* & $29 \%$ & $46 \%$ \\
\hline $11 A^{*}$ & $44 \%$ & $118 \%$ & $17 \mathrm{D}^{* * *}$ & $19 \%$ & - & $30 \mathrm{~B} * *$ & $16 \%$ & - \\
\hline $11 \mathrm{~B} * *$ & $20 \%$ & - & $17 \mathrm{E}^{* *}$ & $22 \%$ & - & $30 C^{*}$ & $23 \%$ & $14 \%$ \\
\hline $11 C^{*}$ & $43 \%$ & $115 \%$ & $18 A^{* *}$ & $29 \%$ & - & $30 D^{*}$ & $34 \%$ & $71 \%$ \\
\hline $11 D^{*}$ & $42 \%$ & $110 \%$ & $18 B^{* *}$ & $14 \%$ & - & Control & $20 \%$ & - \\
\hline
\end{tabular}

(1) Se realizó la prueba de Dunnett al nivel de significación $\alpha=0.05$, para

comparaciones de las medias cada tratamiento con respecto al control sin inocular. a: Valor central I: Porcentaje del incremento de la germinación con relación al control.

* Bacterias que incrementan significativamente el porcentaje de germinación con respecto al control.

** No presentan diferencias significativas en el porcentaje de germinación con respecto al control.

*** Disminuyen significativamente el porcentaje de germinación con respecto al control. 
Tabla 6. Identificación molecular de bacterias diazotróficas nativas aisladas de la rizósfera del olivo (Olea europea) en La Yarada-Tacna.

\begin{tabular}{|c|c|c|c|c|c|c|c|c|c|}
\hline \multirow{3}{*}{ Сера } & \multicolumn{8}{|c|}{ BASES DE DATOS } & \multirow{3}{*}{$\begin{array}{l}\text { Identificación } \\
\text { Género/especie }\end{array}$} \\
\hline & \multicolumn{2}{|c|}{ Blast server for bacterial identification } & \multicolumn{2}{|c|}{ Ribosomal database project } & \multicolumn{2}{|c|}{ Bibi database } & \multicolumn{2}{|l|}{ Ez Taxon } & \\
\hline & Género/especie & Identidad & Género/especie & S_ab score & Género/especie & Identidades & Especie & Similitud & \\
\hline $3 \mathrm{~A}$ & Novosphingobium sp. & $98.00 \%$ & Novosphingobium sp. & $91.40 \%$ & Sphingomonas bosoensis & $98.00 \%$ & $\begin{array}{l}\text { Novosphingobium barchaimii } \\
\text { LL02 (T) }\end{array}$ & $97.70 \%$ & Novosphingobium sp. \\
\hline 3B & Novosphingobium sp. & $98.00 \%$ & Sphingomonas sp. & $91.40 \%$ & Sphingomonas bosoensis & $98.00 \%$ & $\begin{array}{l}\text { Novosphingobium barchaimii } \\
\text { LL02 (T) }\end{array}$ & $97.83 \%$ & Novosphingobium sp. \\
\hline $5 \mathrm{~A}$ & Klebsiella pneumoniae & $99.00 \%$ & K. pneumoniae & $96.60 \%$ & Klebsiella pneumoniae & $99.00 \%$ & $\begin{array}{l}\text { K. pneumoniae subsp. } \\
\text { rhinoscleromatis ATTC 13884(T) }\end{array}$ & $99.82 \%$ & $\begin{array}{l}\text { K. pneumoniae subsp. } \\
\text { rhinoscleromatis }\end{array}$ \\
\hline $7 \mathrm{~A}$ & Agrobacterium tumefaciens & $99.00 \%$ & Rhizobium radiobacter & $96.00 \%$ & Beijerinckia fluminensis & $99.00 \%$ & Rhizobium massiliae 90A & $99.80 \%$ & Rhizobium massiliae \\
\hline $7 \mathrm{~B}$ & Burkholderia sp. & $99.00 \%$ & Burkholderia sp. & $97.60 \%$ & Burkholderia sp. & ND* & $\begin{array}{l}\text { Burkholderia metallica R-16017 } \\
\text { (T) }\end{array}$ & $100.00 \%$ & Burkholderia metallica \\
\hline $9 \mathrm{~F}$ & Novosphingobium sp. & $98.00 \%$ & Novosphingobium sp. & $90.80 \%$ & Novosphingobium sp. & $97.00 \%$ & $\begin{array}{l}\text { Novosphingobium barchaimii } \\
\text { LL02 (T) }\end{array}$ & $97.90 \%$ & Novosphingobium sp. \\
\hline $9 \mathrm{~K}$ & Sphingobium yanoikuyae & $99.00 \%$ & $\begin{array}{l}\text { Sphingobium } \\
\text { yanoikuyae }\end{array}$ & $97.40 \%$ & Sphingobium yanoikuyae & $99.00 \%$ & Sphingobium scionense WP01(T) & $99.61 \%$ & Sphingobium scionense \\
\hline $11 \mathrm{~A}$ & Sphingobium yanoikuyae & $99.00 \%$ & $\begin{array}{l}\text { Sphingobium } \\
\text { yanoikuyae }\end{array}$ & $97.40 \%$ & Sphingobium yanoikuyae & $99.00 \%$ & Sphingobium scionense WP01(T) & $99.82 \%$ & Sphingobium scionense \\
\hline 11D & Azotobacter vinelandii & $99.00 \%$ & Azotobacter vinelandii & $96.40 \%$ & Azotobacter vinelandii & $99.00 \%$ & Azotobacter vinelandii DJ & $99.82 \%$ & Azotobacter vinelandii \\
\hline 11I & Novosphingobium sp. & $98.00 \%$ & Novosphingobium sp. & $92.50 \%$ & Novosphingobium sp. & $97.00 \%$ & $\begin{array}{l}\text { Novosphingobium barchaimii } \\
\text { LL02 (T) }\end{array}$ & $98.00 \%$ & Novosphingobium sp. \\
\hline $12 \mathrm{G}$ & Novosphingobium sp. & $98.00 \%$ & Sphingomonas sp. & $88.30 \%$ & Novosphingobium sp. & $98.00 \%$ & $\begin{array}{l}\text { Novosphingobium panipatense } \\
\text { SM } 16(\mathrm{~T})\end{array}$ & $98.31 \%$ & Novosphingobium sp. \\
\hline 13C & Azotobacter vinelandii & $98.00 \%$ & Azotobacter vinelandii & $91.50 \%$ & Azotobacter vinelandii & $98.00 \%$ & Azotobacter vinelandii DJ & $98.96 \%$ & Azotobacter sp. \\
\hline $14 \mathrm{~A}$ & $\begin{array}{l}\text { Erwinia sp., Pectobacterium } \\
\text { sp. }\end{array}$ & $97.00 \%$ & Erwinia persicina & $92.50 \%$ & Pantoea sp. & $98.00 \%$ & Erwinia tasmanienis Et1/99T & $99.15 \%$ & Erwinia tasmaniensis \\
\hline 14B & Erwinia tasmaniensis & $98.00 \%$ & Erwinia persicina & $92.30 \%$ & Pantoea sp. & $99.00 \%$ & Erwinia tasmanienis Et1/99T & $99.33 \%$ & Erwinia tasmaniensis \\
\hline 16B & $\begin{array}{l}\text { Novosphingobium } \\
\text { resinovorum }\end{array}$ & $99.00 \%$ & Novosphingobium sp. & $99.40 \%$ & N. resinovorum & $99.00 \%$ & N. resinovorum NCIMB 8767 (T) & $99.84 \%$ & $\begin{array}{l}\text { Novosphingobium } \\
\text { resinovorum }\end{array}$ \\
\hline 17C & Bacillus niabensis & $99.00 \%$ & Bacillus sp. & $96.10 \%$ & Bacillus sp. & $98.00 \%$ & Bacillus niabensis 4T19 $(\mathrm{T})$ & $98.84 \%$ & Bacillus sp. \\
\hline $18 \mathrm{~A}$ & Klebsiella oxytoca & $100.00 \%$ & Raoultella planticola & $96.10 \%$ & Raoultella sp. & $99.00 \%$ & $\begin{array}{l}\text { Raoutella planticola DSM } 3069 \\
(\mathrm{~T})\end{array}$ & $99.69 \%$ & Raoultella planticola \\
\hline $26 \mathrm{~B}$ & Sphingobium yanoikuyae & $98.00 \%$ & $\begin{array}{l}\text { Sphingobium } \\
\text { yanoikuyae }\end{array}$ & $95.60 \%$ & Sphingobium yanoikuyae & $99.00 \%$ & Sphingobium scionense WP01(T) & $99.75 \%$ & Sphingobium scionense \\
\hline $27 \mathrm{~F}$ & Novosphingobium sp. & $99.00 \%$ & Novosphingobium sp. & $94.00 \%$ & Sphingomonas bosoensis & $98.00 \%$ & $\begin{array}{l}\text { Novosphingobium barchaimii } \\
\text { LL02 (T) }\end{array}$ & $98.44 \%$ & Novosphingobium sp. \\
\hline
\end{tabular}

Criterio de inclusión: cepas con similitud $>99$ \% se consideraron como especie identificada. 
1 Laboratorio CITELAB del Módulo de Servicios Tacna CITE Agroindustrial. Panamericana Sur Km 1303 Ciudadela ZOFRATACNA-Perú. Correspondencia electrónica: lbiondi@olivosbiondi.com

2 Laboratorio de Ecología Microbiana y Biotecnología Marino Tabusso, Dpto. de Biología Universidad Nacional Agraria La Molina. Av. La Molina S/N La Molina, Lima - Perú, Dirección electrónica dzuniga@lamolina.edu.pe 